\title{
Study on Organic Modification of Attapulgite with Silane Coupling Agents KH570
}

\author{
Lingling Wang \\ Department of Materials Chemistry \\ Huzhou University \\ Huzhou, China \\ e-mail: 1913570779@qq.com \\ Yuanyuan Lv \\ Department of Materials Chemistry \\ Huzhou University \\ Huzhou, China \\ e-mail: 825516385@qq.com
}

\author{
Ting Wang \\ Department of Materials Chemistry \\ Huzhou University \\ Huzhou, China \\ e-mail: 1175115833@qq.com \\ Minhong Xu \\ Department of Materials Chemistry \\ Huzhou University \\ Huzhou, China \\ e-mail: xumh123@163.com
}

\begin{abstract}
In order to improve the adsorption performance of Attapulgite (ATP) on dyes. The ATP activated with hydrochloric acid was organic modified with silane coupling agent KH570. And the modified attapulgites was characterized by Fourier transform infrared spectroscopy and $\mathrm{X}$-ray diffraction technique. By evaluating the activation index, the optimum modified condition as follow: KH570 dosage was $30 \mathrm{wt} \%$, based on the quality of ATP, the modified time was $2 \mathrm{~h}$ and modified temperature was $80^{\circ} \mathrm{C}$. The results of adsorption experiments suggested that the modified attapulgite had a higher adsorption capacity for removing methylene blue. While adsorption of methylene blue on KH570-ATP, the decoloration rate increased to $79.55 \%$. Owing to its high absorption capacity and low cost, attapulgite modified with KH570 has potential value in the removal of methylene blue waste waters in engineering application.
\end{abstract}

Keywords-silane coupling agent KH570; attapulgite; hydrochloric-acid; organic modification; activation index

\section{INTRODUCTION}

Attapulgite clay (ATP) is a natural crystalline hydrated magnesium silicate with a fibrous morphology [1]. The large specific surface area and high cation exchange capacity of ATP make it suitable to remove cation ions. Nevertheless, the absorption capacity of natural ATP is limited, so it needs to be modified to improve its absorption ability. The reported modifiers such as 3aminpropyltriethoxysilane [2], ammonium citrate tribasic [3], chitosan [4,5]. Zhou et al. found that the bunchy aggregation of attapulgite was dispersed by CTAB modification and the surface of attapulgite was endowed with organic structure [6]. J. Zhang also reported removal of fluoride ions from aqueous solution using modified attapulgite as adsorbent [7]. Attapulgite modified with hexadecyltrimethylammonium bromide was effective to remove the congo red anionic dye (H. Chen, J. Zhao) [8]. A. Xue also reported that silylated ATP was effective to remove the reactive dyes [9]. Note that there are large high quality reserves of ATP clays in Xuyu, Jiangsu province of
China, thus modified ATP has potential to be an effective and low-cost sorbent for dye wastewater treatment.

In this paper, the modification of ATP with silane coupling agent KH570 was investigated. The modified ATP was characterized by Fourier transform infrared spectroscopy and X-ray diffraction technique. The factors of modified agent dosage, temperature and time were systemically investigated by evaluating the activation index, and their feasibility for removing methylene blue from solution was also discussed.

\section{EXPERIMENTAL}

\section{A. Materials}

The pristine ATP clay powder was supplied by Jiangsu Junda Attapulgite Material Co., Ltd. with mesh number is 200. KH570 (Nanjing DebioChem Co. Ltd., China) was analytical grade and used as received. Methylene blue, glacial acetic acid, ethanol and other common reagents were purchased from Aladdin Industrial Corporation (Shanghai, China).

\section{B. The Modification of ATP}

The attapulgite need to be pretreated with acid before modification. Briefly, ATP and hydrochloric acid (4 mol/L) were placed in $250 \mathrm{~mL}$ three neck flask; constant stirring for $24 \mathrm{~h}$ at $70^{\circ} \mathrm{C}$, the ratio of solid to liquid was $1: 10$. Then, ATP was washed with distilled water until neutralization, and dried at $110^{\circ} \mathrm{C}$ for $8 \mathrm{~h}$.

According to the literatures, the hydrolysis of silane coupling agent KH570 was as follow: KH570, distilled water and ethanol were placed in a beaker; the volume ratio was $1: 1: 18$. And stirring in magnetic for $3 \mathrm{~h}$ at room temperature, the $\mathrm{pH}$ value of solution was in range of 4 to 6 , adjusted with acetic acid solution.

KH570 modified attapulgite (KH570-ATP) was prepared mainly according to the method reported previously [10]: $5 \mathrm{~g}$ of acid activated ATP and $150 \mathrm{~mL}$ distilled water were placed in beaker, the solution was adjusted by adding $2 \mathrm{~mol} / \mathrm{L} \mathrm{NaOH}$ solution until the $\mathrm{pH}$ 
value was about 3, and scattering about 20 min under ultrasonic. After that solution mentioned above and the prepared KH570 were placed in $250 \mathrm{~mL}$ three neck flask and stirring at $80^{\circ} \mathrm{C}$ for $2 \mathrm{~h}$. The reactants were filtrated in vacuum varied and washed with distilled water with several times, and dried at $105^{\circ} \mathrm{C}$ to constant weight.

\section{Determination of the Activation Index}

$5 \mathrm{~g}$ KH570-ATP was added in $100 \mathrm{~mL}$ distilled water and ultrasonic dispersing for $20 \mathrm{~min}$, and then standing. Afterwards, the materials that deposited in the bottom of the beaker were separated, dried and weighed. The mass of the floating part of KH570-ATP was obtained through the original quality minus the subsidence. The activation index was got by calculating with the equation as follow:

Activation index $=\left(\mathrm{W}_{1}-\mathrm{W}_{2}\right) / \mathrm{W}_{1} \times 100 \%$

where $\mathrm{W}_{1}$ is the original quality, $\mathrm{W}_{2}$ is the mass of subsidence, and $\left(\mathrm{W}_{1}-\mathrm{W}_{2}\right)$ means the mass of the floating part. The higher the activation index, the better the modification effect is.

\section{Adsorption Experiments}

The KH570-ATP (0.1 g) mentioned above were immersed in methylene blue solution $(10 \mathrm{mg} / \mathrm{L}, 50 \mathrm{~mL})$, while stirring $(130 \mathrm{r} / \mathrm{min})$ at $25{ }^{\circ} \mathrm{C}$. A certain volume of supernatant liquor was taken out and analyzed on a 722 spectrophotometer using distilled water as reference at $\lambda \max$ of $664 \mathrm{~nm}$. The adsorption efficiency was calculated using the following equation:

Decoloration rate $=\left(\mathrm{C}_{0}-\mathrm{C}_{\mathrm{t}}\right) / \mathrm{C}_{0} \times 100 \%$

where $\mathrm{C}_{0}$ is the initial concentration of methylene blue solution, $\mathrm{C}_{\mathrm{t}}$ is the concentration of methylene blue solution after a certain reaction time.

\section{RESULTS AND DISCUSSION}

\section{A. XRD Analysis of Attapulgite}

The X-ray diffraction (XRD) patterns were recorded on $\mathrm{XD}-6$ diffractometer with $\mathrm{Cu} \mathrm{Ka}$ radiation $(\lambda=0.15406 \mathrm{~nm})$ target $(36 \mathrm{kV}, 20 \mathrm{~mA})$ at a scanning rate of $2 \% \mathrm{~min}$. The X-ray diffraction (XRD) pattern of KH570-ATP was shown in Fig. 1. The typical diffraction peaks at $2 \theta$ was $8.3^{\circ}, 19.7^{\circ}$ and $26.9^{\circ}$ in Fig. 1 (a) shown good agreement with primary diffraction of the (110), (040) and (400) planes of the attapulgite [11]. After modified with KH570, the important diffraction peaks show no shift in Fig. 1 (b) compared with attapulgite, which proved KH570 did not change the original crystal structure of attapulgite. The invariability of d-spacing of KH570-ATP suggests that the modification of attapulgite with KH570 was on the surface.

\section{B. FT-IR Analysis of Modified Attapulgite}

Fourier transform infrared (FT-IR) spectra of the materials were acquired on a Nicolet 5700 FT-IR spectrometer (Thermo Nicolet, USA) using $\mathrm{KBr}$ pressing method. IR spectra of unmodified attapulgite and those modified with KH570 were presented in Fig. 2. There was broad band at around $3571 \mathrm{~cm}^{-1}$ and $3434 \mathrm{~cm}^{-1}$ in IR spectra curve a (ATP) were attributed to the stretching vibrations of -OH groups. The absorption peaks at 1662 $\mathrm{cm}^{-1}$ was ascribed to the bending vibrations of -OH groups. In addition, the absorption peaks at $1079 \mathrm{~cm}^{-1}$ was ascribed to the stretching vibrations of -Si-O-Si groups [12]. The absorption peaks at $1472 \mathrm{~cm}^{-1}$ just as curve b (KH570) shown was attributed to the stretching vibration $\mathrm{C}-\mathrm{O}, \mathrm{C}-\mathrm{N}$, and $\mathrm{C}-\mathrm{C}$ of $\mathrm{KH} 570$. The new peaks in the spectrum of KH570-ATP (Fig. 2c) appearing at about $1440 \mathrm{~cm}^{-1}$ attributed to the stretching vibration $\mathrm{C}-\mathrm{O}, \mathrm{C}-\mathrm{N}$, and $\mathrm{C}-\mathrm{C}$ of KH570. The peak at about $3582 \mathrm{~cm}^{-1}$ became broader than that of ATP probably due to the N-H stretching vibration of KH570. The results suggested that the silane coupling agent KH570 has been loaded onto the surface of ATP.

\section{Effect of KH570 dosage}

The effects of KH570 dosage on surface modification of ATP were investigated at modified temperature $80{ }^{\circ} \mathrm{C}$ and modification time $2 \mathrm{~h}$. The KH570 were $10 \mathrm{wt} \%, 15$ $\mathrm{wt} \%, 20 \mathrm{wt} \%, 25 \mathrm{wt} \%$ and $30 \mathrm{wt} \%$, respectively, based on the quality of ATP, the results shown in Fig. 3.

From the Fig. 3, when the dosage was $10 \mathrm{wt} \%$, the activation index was $16.76 \%$. When the dosage was 15 $\mathrm{wt} \%$, the activation index was $31.33 \%$. The activation index of ATP increased obviously with the increasing of KH570 dosage, especially the KH570 dosage reached 20 $\mathrm{wt} \%$, the activation index was $36.84 \%$ and the modified effect was best. However, added the KH570 dosage to 25 wt $\%$, the activation index was $36.84 \%$, the activation index not increased as the KH570 dosage increased to 20 wt $\%$. The optimal KH570 dosage was found to be $30 \mathrm{wt} \%$, based on the quality of ATP, as the activation index was $36.84 \%$.

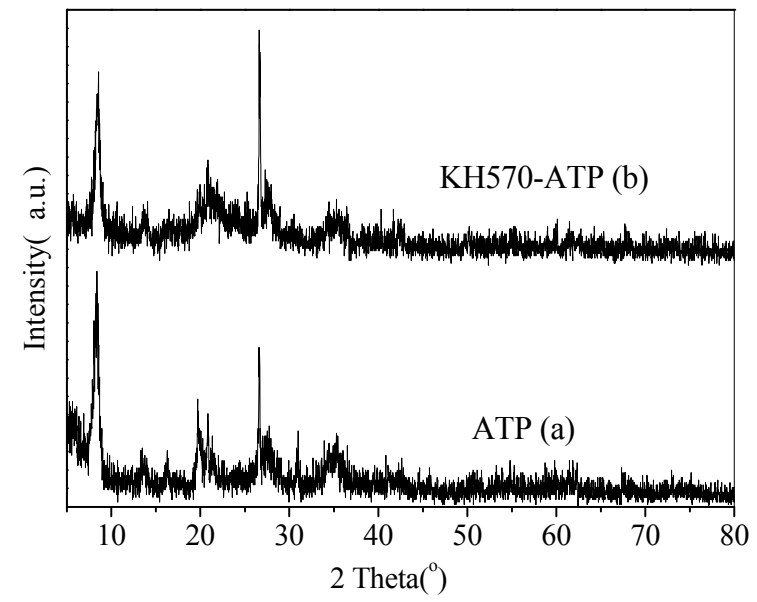

Figure 1. X-ray diffraction patterns of ATP(a) and KH570-ATP(b)

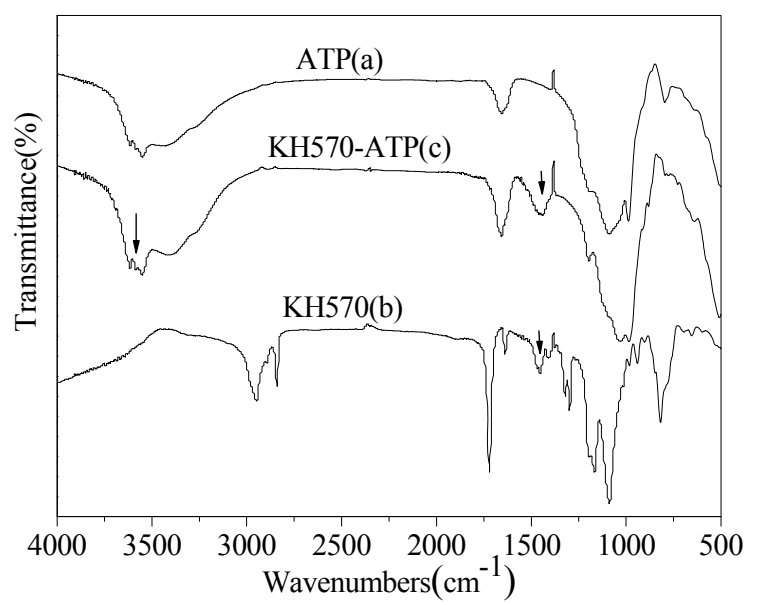

Figure 2. FT-IR spectras of ATP (a), KH570 (b) and KH570-ATP (c) 


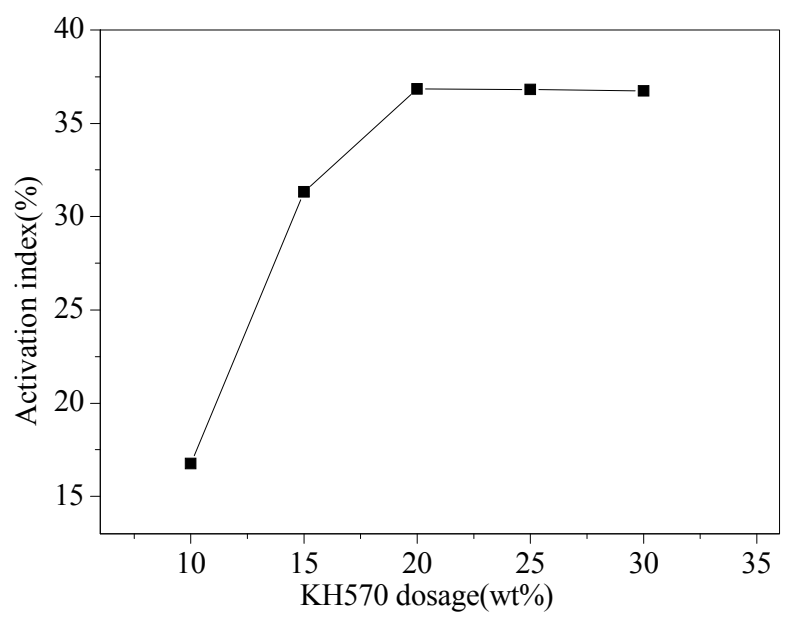

Figure 3. Effects of KH570 dosage on modification of ATP (modification temperature $80{ }^{\circ} \mathrm{C}$ and modification time $2 \mathrm{~h}$ )

\section{Effect of Ttemperature}

The effect of temperature on modification of ATP, which was evaluated by activation index, was researched in the condition of modifier dosage KH570 was $20 \mathrm{wt} \%$ and modified time was $2 \mathrm{~h}$, the results shown in Fig. 4. When the temperature was $30^{\circ} \mathrm{C}$, the activation index was $22.88 \%$. While the temperature reached to $50{ }^{\circ} \mathrm{C}$, the activation index was $28.07 \%$. When the temperature was $70{ }^{\circ} \mathrm{C}$, the activation index was $31.92 \%$. The activation index of ATP could reach its highest value $36.84 \%$ as temperature reached to $80{ }^{\circ} \mathrm{C}$. The activation index decreased to $32.50 \%$ while the temperature increased to $90{ }^{\circ} \mathrm{C}$.

This was because when the temperature was low, the ion adsorption reaction was dominant. While temperature gradually increased, condensation reaction was dominant, so the activation index increased. But the temperature continued increased, the activation index was reduced, this may be due to desorption between KH570 and ATP, which leaded to the modification effect reduced. The optimal modification temperature was $80{ }^{\circ} \mathrm{C}$.

\section{E. Effect of Contact Time}

The effects of modification time were researched at modification temperature was $80{ }^{\circ} \mathrm{C}$ and modifier dosage KH570 was $20 \mathrm{wt} \%$, the results shown in Fig. 5. When the reaction time reached $0.5 \mathrm{~h}$, the activation index of ATP was $12.80 \%$. When reaction time increased to $1 \mathrm{~h}$, the activation index was $28.42 \%$. When reaction time increased to $1.5 \mathrm{~h}$, the activation index was $32.40 \%$. When reaction time increased to $2 \mathrm{~h}$, the activation index could reach its highest value $36.84 \%$. If we continued to extend the reaction time to $2.5 \mathrm{~h}$, the activation index decreased to $36.06 \%$. The possible reason was that the modifier had not reacted adequately on ATP superficial in short time. When the time increased to $2 \mathrm{~h}$, the modified reaction was adequately. While continuing to extend the reaction time, the mechanical agitation could destruct the combination between KH570 and ATP. From that the optimal reaction time for this experiment was $2 \mathrm{~h}$.

\section{F. Absorption of Methylene Blue}

In order to study the adsorption properties of KH570ATP, the experiments that adsorption of methylene blue were carried out under the conditions of KH570-ATP $0.1 \mathrm{~g}$, methylene blue $10 \mathrm{mg} / \mathrm{L}, 50 \mathrm{~mL}, 25^{\circ} \mathrm{C}$, the results shown in Fig. 6. As shown in Fig. 6, the decoloration rate of adsorption of methylene blue on ATP was increased with increasing of time; the decoloration rate was $61.36 \%$ after adsorption for $40 \mathrm{~min}$. While adsorption of methylene blue on KH570-ATP, the decoloration rate increased to $79.55 \%$. Combined with the above results, it indicated that KH570-ATP was more efficient to remove methylene blue from aqueous solution.

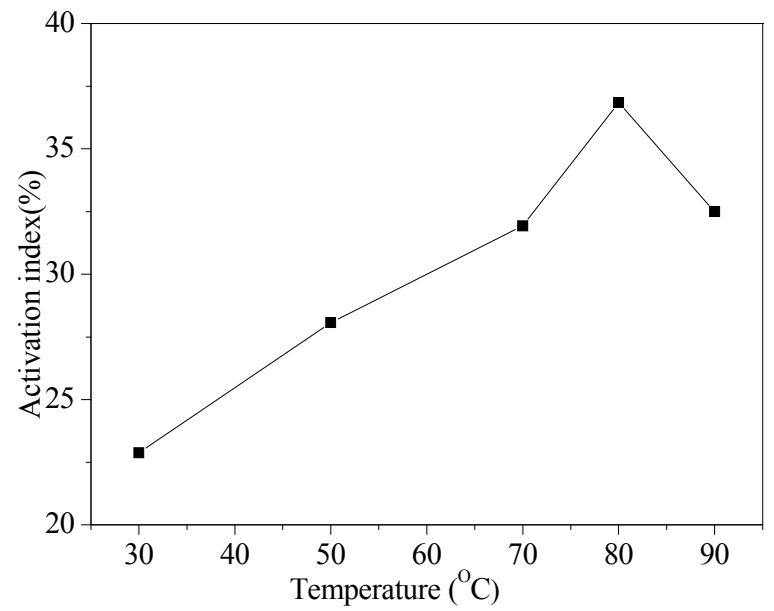

Figure 4. Effect of temperature on modification of ATP (KH570 dosage $20 \mathrm{wt} \%$ and modification time $2 \mathrm{~h}$ )

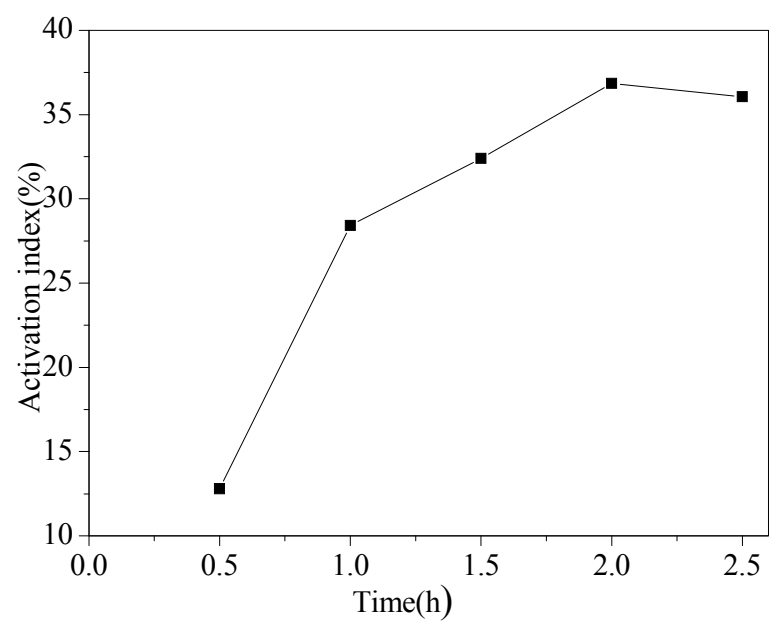

Figure 5. Effect of time on modification of ATP (KH570 dosage 20 wt $\%$ and temperature $80{ }^{\circ} \mathrm{C}$ ) 


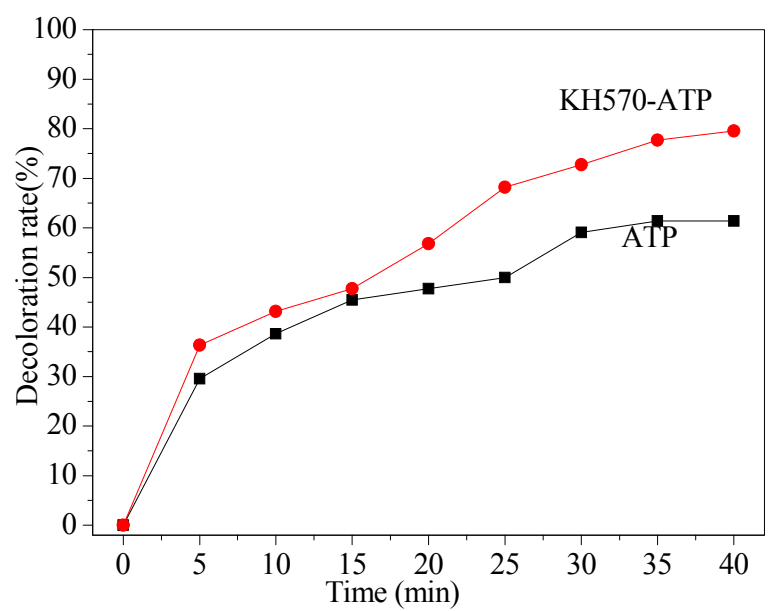

Figure 6. Absorption of methylene blue on KH570 modified ATP(KH570-ATP $0.1 \mathrm{~g}$, methylene blue $\left.10 \mathrm{mg} / \mathrm{L}, 50 \mathrm{~mL}, 25^{\circ} \mathrm{C}\right)$

\section{CONCLUSIONS}

The attapulgites (ATP) activated with hydrochloric acid was organic modified with silane coupling agent KH570 to prepare novel adsorbent. The modified attapulgites was characterized by Fourier transform infrared spectroscopy and X-ray diffraction technique. The results demonstrated that the silane coupling agent KH570 has been loaded onto the surface of ATP. By evaluating the activation index, the optimum modified condition as follow: KH570 dosage was $30 \mathrm{wt} \%$, based on the quality of ATP, the modified time was $2 \mathrm{~h}$ and modified temperature was $80{ }^{\circ} \mathrm{C}$. The results of adsorption experiments suggested that the modified attapulgite had a higher adsorption capacity for removing methylene blue.

\section{REFERENCES}

[1] Y. Deng, F. Wu, B. Liu, X. Hu and C. Sun, "Sorptive removal of $\beta$-blocker propranolol from aqueous solution by modified attapulgite: Effect factors and sorption mechanisms," Chemical Engineering Journal, vol. 174, Nov. 2011, pp. 571-578, doi: 10.1016/j.cej.2011.09.057.

[2] F. Liang, B. Liu, Y. Deng, S. Yang and C. Sun, "Preparation and characterization of attapulgite-silver nanocomposites, and their application to the electrochemical determination of nitrobenzene, " Microchimica Acta, vol. 174, Jun. 2011, pp. 407-412, doi: 10.1007/s00604-011-0647-7.

[3] T. Hu and L. Tan, "Modifying attapulgite clay by ammonium citrate tribasic for the removal of radionuclide Th(IV) from aqueous solution," Journal of Radioanalytical and Nuclear Chemistry, vol. 292, May. 2012, pp. 819-827, doi: 10.1007/s10967-011-1522-z.

[4] X. Zou, J. Pan, H. Ou, X. Wang, W. Guan and C. Li, "Adsorptive removal of $\mathrm{Cr}$ (III) a nd $\mathrm{Fe}$ (III) from aqueous solution by chitosan/attapulgite composites: equilibrium, thermodynamics and kinetics," Chemical Engineering Journal, vol. 167, Feb. 2011 pp.112-121, doi: 10.1016/j.cej.2010.12.009.

[5] C. Pang, Y. Liu, X. Cao, R. Hua, C. Wang and C. Li , "Adsorptive removal of uranium from aqueous solution using chitosan-coated attapulgite," Journal of Radioanalytical and Nuclear Chemistry, vol. 286, Otc. 2010, pp.185-193, doi: 10.1007/s10967-010-0635-0.

[6] S. Zhou, G. Li and Y. Lv, "CTAB modification of attapulgite and its inhibition to algae growth," Materials for Renewable Energy and Environment, vol. 2, Jan. 2011, pp. 2062-2065, doi: 10.1109/ICMREE.2011.5930743.

[7] J. Zhang, S. Xie and Y. Ho, "Removal of fluoride ions from aqueous solution using modified attapulgite as adsorbent," Journal of Hazardous Materials, vol. 165, Nov. 2009, pp. 218-222, doi: 10.1016/j.jhazmat.2008.09.098.

[8] H. Chen and J. Zhao, "Adsorption study for removal of Congo red anionic dye using organo-attapulgite," Adsorption, vol. 15, Aug. 2009, pp. 381-389, doi: 10.1007/s10450-009-9155-z.

[9] A. Xue, S. Zhou, Y. Zhao, X. Lu and P. Han, "Adsorption of reactive dyes from aqueous solution by silylated palygorskite," Applied Clay Science, vol. 48, May. 2010, pp. 638-640, doi: 10.1016/j.clay.2010.03.011.

[10] P. Liu and T. Wang, "Hyperbranched aliphatic polyester grafted attapulgite via a melt polycondensation process," Applied Clay Science, vol. 35, Nov. 2007, pp. 11-16, doi: 10.1016/j.jhazmat.2007.03.048.

[11] W. Zhu, Z. Liu, L. Chen and Y. Dong, "Sorption of uranium(VI) on Na-attapulgite as a function of contact time, solid content, $\mathrm{pH}$, ionic strength, emperature and humic acid," Journal of Radioanalytical and Nuclear Chemistry, vol. 289, Sep. 2011, pp. 781-788, doi: 10.1007/s10967-011-1129-4.

[12] D. M. A. Melo, J. A. C. Ruiz, M. A. F. Melo, E.V Sobrinho, and M Schmall, "Preparation and characterization of terbium palygorskite clay as acid catalyst," Microporous and Mesoporous Materials, vol. 38, Aug. 2000, pp. 345-349, doi: 10.1016/S13871811(00)00155-4. 